\title{
IMPLEMENTASI CORPORATE GOVERNANCE GUNA MENINGKATKAN SUSTAINABILITY MANAGEMENT DAN DAMPAKNYA TERHADAP MASYARAKAT
}

\author{
Ahmad Sugianto*, Hamidah \\ Magister Akuntansi, Fakultas Ekonomi dan Bisnis, Universitas Airlangga, Surabaya, Indonesia \\ *Penulis Korespondensi: ahsugianto@yahoo.co.id
}

\begin{abstract}
Abstrak
Corporate governance yang sehat menjadi sangat penting agar perusahaan dapat bersaing secara kompetitif namun tetap mengedepankan etika bersaing sehingga dapat meningkatkan sustainability management perusahaan. Dengan konsep going green yang diwujudkan dalam kegiatan CSR berimplikasi terhadap kesejahteraan masyarakat. Masalah kajian ditujukan pada bagaimana implementasi corporate governance dengan adanya konsep going green guna meningkatkan sustainability management. Tujuannya adalah untuk mengungkap bagaimana implimentasi tersebut berdampak terhadap masyarakat. Teori Komunitarian digunakan untuk menjelaskan permasalahan yang diungkap. Berbagai bahan literatur digunakan dalam pembahasan dengan metode kajian literatur. Hasil kajian memperlihatkan peran pro aktif perusahaan-perusahaan untuk mendukung pelaksanaan CSR dan diperkuat dengan dukungan Pemerintah Pusat dan Daerah. Disimpulkan bahwa kerjasama antara Pemerintah Pusat dan Daerah dengan perusahaan-perusahaan yang melaksanakan CSR menjadi faktor penentu bagi keberhasilan CSR sehingga dapat memberikan kesejahteraan hidup ke masyarakat.
\end{abstract}

Kata kunci: Corporate Governance; Sustainability Management; Going Green; CSR.

\begin{abstract}
Healthy corporate governance becomes very important so that companies can compete competitively while still promoting competitive ethics so as to improve the company's sustainability management. With the concept of going green which is embodied in CSR activities has implications for the welfare of society. The study problem is aimed at how the implementation of corporate governance with the concept of going green in order to improve sustainability management. The aim is to uncover how the implications have impacted society. Communitarian Theory is used to explain the problem revealed. Various literary materials are used in the discussion with the literature review method. The results of the study show the pro-active role of companies in supporting the implementation of CSR and strengthened with the support of the Central and Regional Governments. It was concluded that the collaboration between the Central and Regional Governments with companies implementing CSR became a determining factor for the success of CSR so as to provide welfare to the community.
\end{abstract}

Keywords: Corporate Governance; Sustainability Management; Going Green; CSR.

\section{PENDAHULUAN}

Corporate governance telah menjadi suatu tuntutan bagi setiap perusahaan agar dapat mempertahankan dan meningkatkan kelanjutan bisnis di tengah persaingan bisnis modern yang semakin kompetitif dan harus dapat dipertanggungjawabkan kepada stakeholders. Chen (2019a) mendefinisikan corporate governance sebagai suatu sistem aturan, praktik, dan proses di mana perusahaan diarahkan dan dikendalikan. Pada dasarnya, corporate governance merupakan penyeimbang berbagai kepentingan stakeholders seperti pemegang saham, eksekutif manajemen senior, pelanggan, pemasok, pemodal, pemerintah, dan masyarakat. Tujuan yang hendak dicapai adalah meningkatkan standar pengelolaan perusahaan sehingga dapat dicapai standar pengelolaan yang tinggi dan merefleksikan kepentingan jangka panjang stakeholders tersebut. Corporate governance memberikan kerangka kerja (framework) bagi perusahaan untuk mencapai tujuannya yang mencakup semua bidang manajemen, yang dimulai dari rencana aksi dan pengendalian internal sampai kepada pengukuran kinerja dan pengungkapan (disclosure) perusahaan.

Menurut Bradley dkk. (2000) terdapat 5 (lima) kekuatan perubahan yang memiliki implikasi mendalam bagi corporate governance dan menjadi ciri internal organisasi dan lingkungan eksternal perusahaan publik yaitu:

1. Perubahan pada sifat pekerjaan

Perkembangan teknologi informasi, komunikasi, dan otomatisasi telah mengubah sifat pekerjaan yang 
telah bergulir sejak revolusi industri di awal abad ke18.

2. Perubahan pada pasar modal

Lingkungan pasar modal telah berubah drastis sejak 20 hingga 40 tahun yang lalu, dimana saat ini telah muncul berbagai instrumen keuangan dan digitalisasi transaksi.

3. Perubahan pada persaingan pasar produk Globalisasi pasar produk perusahaan bukan lagi berita baru, namun yang menjadi berita aktual adalah luas dan percepatan dari fenomena ini.

4. Perubahan pada bentuk organisasi.

Telah muncul berbagai bentuk organisasi paska bergulirnya revolusi industri, seperti organisasi jejaring, perusahaan modular, perusahaan vitual, perusahaan horisontal, dan organisasi tanpa batas.

5. Perubahan pada Lingkungan regulasi

Paska perang dunia I dan II berakhir telah ada kesibukan luar biasa di Amerika Serikat terkait aktivitas regulasi terutama atas penyediaan modal bagi perusahaan. Perkembangan regulasi yang paling menonjol adalah dengan disahkannya Undang-Undang Bursa Efek tahun 1934.

Kelima kekuatan perubahan di atas menjadi perhatian utama bagi sebagian besar perusahaan di seluruh belahan dunia yang peduli terhadap keberlangsungan bisnis yang selaras dengan tuntutan perubahan sehingga dapat mendorong perusahaan untuk berusaha dan memiliki corporate governance yang sehat. Sebaliknya, pelaksanaan corporate governance yang buruk dapat menimbulkan keraguan dalam diri pemegang saham terhadap perusahaan atas keandalan, integritas, dan kewajiban perusahaan sehingga akhirnya berimplikasi terhadap kesehatan keuangan perusahaan.

Pada dasawarsa terakhir ini telah muncul fenomena going green yaitu konsep perusahaan-perusahaan untuk menerapkan metode hidup ramah lingkungan, teknologi ramah lingkungan, pilihan utilitas ramah lingkungan, dan penawaran produk serta layanan ramah lingkungan. Fenomena ini mendasari perusahaan melakukan reorientasi tujuan perusahaan, terlebih lagi saat ini telah ada pergeseran tuntutan stakeholder terutama pemegang saham terhadap perusahaan. Kebanyakan pemegang saham tersebut menuntut tidak hanya sekedar keuntungan finansial melainkan juga merambah pada berbagai kegiatan perusahaan yang berdampak luas terhadap lingkungan seperti kesadaran lingkungan, perilaku etis, dan praktik corporate governance yang sehat (Chen, 2019a). Praktik corporate governance yang sehat ini akhirnya akan menciptakan transparansi pada perangkat aturan dan pengendalian perusahaan. Sebagai implikasinya, insentif yang diperoleh pemegang saham, direktur, dan pejabat lainnya ditentukan berdasarkan praktik corporate governance yang sehat.

Untuk mencapai tujuan perusahaan yang berlandaskan going green diperlukan adanya penerapan konsep sustainability management. Hoffman (2001) menguraikan lebih lanjut konsep sustainability management menjadi sustainability (keberlanjutan) dan mensintesisnya dengan konsep manajemen. Sustainability memiliki tiga cabang yaitu lingkungan, kebutuhan generasi sekarang dan mendatang, dan ekonomi. Dengan memanfatkan ketiga cabang ini, sustainability menciptakan kemampuan sistem untuk berkembang dengan mempertahankan kelayakan ekonomi dan juga memenuhi kebutuhan generasi sekarang dan mendatang melalui pembatasan deplesi sumber daya.

Sustainability management diperlukan karena merupakan bagian penting dari kemampuan untuk mempertahankan kualitas hidup dan dapat diterapkan pada pada semua aspek kehidupan, misalnya praktik bisnis harus berkelanjutan jika ingin bertahan dalam bisnis, karena bila bisnis tidak lagi berkelanjutan maka perusahaan tidak dapat menghadapi persaingan. Taufik (2019) mengidentifikasi beberapa manfaat implementasi sustainability management bagi perusahaan yaitu:

1. Perusahaan lebih peduli terhadap masyarakat dan lingkungan sekitar dalam pembangunan komunitas (community development) atau Corporate Social Responsibility (CSR).

2. Perusahaan bukan hanya mengejar keuntungan bagi pemilik semata, namun juga harus menjaga dan memberi nilai tambah (value added) pada masyarakat dan lingkungannya.

3. Meningkatkan nama baik / reputasi perusahaan sehingga terjaga citra (image) yang positif.

4. Mengurangi dampak risiko yang merugikan perusahaan

5. Meningkatkan daya saing perusahaan (competitive advantage)

6. Meningkatkan kepercayaan para pemegang saham dan stakeholders lainnya.

7. Bahan Analisis investasi bagi para investor (Socially Responsible Invesment / SRI).

Lebih lanjut Hoffman (2001) menjelaskan bahwa masyarakat sangat membutuhkan sustainability management, karena jika masyarakat ingin makmur maka manajemen harus menjalankan konsep berkelanjutan. Hutan dan sumber daya alam perlu memiliki sustainability management jika ingin dapat terus digunakan oleh generasi sekarang dan generasi mendatang. Kehidupan masyarakat perlu dikelola secara berkelanjutan yaitu dengan membuat keputusan yang akan membantu mempertahankan keadaan sekitar dan lingkungan. Sustainability management ini juga dapat diterapkan pada banyak hal sebagai konsep literal dan abstrak, artinya bahwa penerapannya tergantung pada bagaimana banyak hal tersebut diterapkan di lingkungan masyarat.

Penerapan sustainability management di lingkungan masyarakat diantaranya berupa kegiatan Corporate Social Responsibility (CSR). Chen (2019b) mendefinisikan CSR sebagai model bisnis yang membantu perusahaan menjadi akuntabel secara sosial, dimana pelaksanaan CSR membuat perusahaan 
menyadari dampak terhadap semua aspek sosial (ekonomi, sosial, dan lingkungan). Penerapan CSR telah diatur Undang-Undang Nomor 40 Tahun 2007 tentang Perseroan Terbatas Pasal 74 ayat (1), (2), (3), dan (4). Selain berbagai kegiatan perusahaan yang bersifat sosial kemasyarakatan, di beberapa perusahaan khususnya perusahaan-perusahaan yang berbadan hukum milik negara telah dibentuk secara formal unit bagian PKBL (Program Kemitraan Bina Lingkungan) yang mengacu pada Undang-Undang Nomor 19 Tahun 2003 tentang Badan Usaha Milik Negara (BUMN) dan diperkuat dengan Peraturan Menteri BUMN Nomor Per-05/MBU/2007. Untuk kegiatan operasional PKBL dibiayai dari sisihan laba bersih perusahaan yaitu sebesar 2\% untuk Program Kemitraan dan 2\% untuk Program Bina Lingkungan.

\section{BAHAN DAN METODE}

Dasar teori yang melandasi kajian ini merujuk pada Teori Komunitarian (Communitarian Theory). Sites (1998) menjelaskan teori ini sebagai pendekatan non politis menuju peremajaan budaya politis yang demokratis, dimana menyoroti kerja sama, koordinasi dan pembangunan konsensus atau pengendalian diri yang bertentangan dengan konflik dan tekanan. Lebih lanjut dijelaskan teori ini dari sisi perusahaan sebagai entitas hukum yang mempunyai implikasi sosial, politis, historis, dan ekonomis. Hal ini berarti bahwa perusahaan adalah entitas yang memiliki hak dan tanggung jawab seperti hanya manusia yang memiliki kemampuan untuk melakukan aktivitas yang baik ataupun buruk. Teori komunitarian menekankan pada (a) perusahaan harus responsif kepada kepentingan stakeholders dan (b) keadilan dan kerjasama antar anggota masyarakat. Teori ini berpendapat bahwa aturan hukum mempunyai peranan penting untuk membatasi perilaku manajemen. Tanpa adanya batasan hukum, terdapat kemungkinan manajemen tidak akan bertanggungjawab baik kepada pemegang saham maupun kepada masyarakat.

Kajian terkait corporate governance dan sustainability management saat ini telah menjadi tren dalam berbagai topik penelitian ilmiah. Masing-masing kajian tersebut mempunyai konteks pembahasan yang berbeda-beda dan adakalanya spesifik pada permasalahan tertentu. Penulis mengangkat pembahasan pada konteks implementasi corporate governance di berbagai perusahaan di Indonesia secara umum dan bagaimana implementasinya dapat meningkatkan sustainability management perusahaan, selanjutnya mengungkap bagaimana dampaknya terhadap lingkungan masyarakat diantaranya melalui kegiatan Corporate Social Responsibility (CSR). Kajian yang diungkap oleh penulis bersifat umum berdasarkan berbagai fenomena atau kejadian sosial yang terjadi saat ini yaitu adanya gerakan going green dalam lingkup yang lebih luas, bukan hanya sekedar kepedulian perusahaan terhadap konservasi lingkungan hidup melainkan lebih luas ke lingkungan ekonomi dan sosial kemasyarakatan.
Penulis mendasarkan kajian pada berbagai rujukan literatur yang bersumber dari buku, buku elektronik, artikel internet, laporan CG Watch 2018, dan jurnaljurnal penelitian ilmiah. Kajian dalam pembahasan ini disebut juga sebagai kajian literatur, sebagaimana yang telah dijelaskan oleh Fraenkel dkk. (2012) bahwa kajian literatur digunakan untuk mengkaji berbagai permasalahan tertentu yang bersifat khusus sehingga dapat diperoleh gambaran masalah yang dikaji, dukungan teoritis konseptual, dan sebagai bahan pembahasan. Masing-masing rujukan literatur tersebut dikaji untuk mengungkap adanya fenomena tertentu, selanjutnya dicari penelitian-penelitian yang mendukung ataupun bertentangan dengan fenomena. Setelah itu ditarik kesimpulan pembahasan yang dapat digeneralisir.

\section{HASIL DAN PEMBAHASAN}

Berdasarkan laporan 2 (dua) tahunan Asian Corporate Governance Association (ACGA) yang dituangkan dalam CG Watch 2018, total skor corporate governance perusahaan-perusahaan di Indonesia telah mengalami kenaikan dari 50,9\% di tahun 2016 menjadi 52\% di tahun 2018. Hal ini tidak terlepas dari semakin membaiknya implementasi corporate governance di masing-masing perusahaan di Indonesia baik dari sektor swasta maupun sektor milik pemerintah, dalam artian bahwa perusahaan-perusahaan secara umum telah mempunyai kerangka strategi yang jelas sebagai roadmap bagi kemajuan perusahaan. Didukung pula dengan semakin maraknya perkembangan dan implementasi going green di perusahaan-perusahaan Indonesia sebagai imbas dari gerakan global going green, yang tercermin dari kenaikan indikator Environment and Social (E/S) dari 57,8\% di tahun 2016 menjadi 59,2\% di tahun 2018. Secara umum, corporate governance perusahaan-perusahaan ini mempengaruhi perekonomian nasional dan menjadi indikator investasi penting bagi para investor luar negeri untuk menanamkan modalnya di Indonesia. Walaupun lambat, peningkatan corporate governance telah membawa harapan untuk meningkatkan penanaman modal luar negeri sehingga lingkungan bisnis dalam negeri menjadi lebih kondusif. Khusus untuk perusahaan-perusahaan milik pemerintah, sebagai bentuk pengawasan regulasi, mulai tahun 2011 Pemerintah Indonesia melalui Kementerian BUMN telah menetapkan Peraturan Menteri BUMN Nomor Per-01/MBU/2011 tentang Penerapan GCG pada BUMN. Sedangkan pada perusahaan-perusahaan swasta, regulasi tidak seketat di perusahaan-perusahaan milik pemerintah namun secara umum sebagai bentuk pertanggungjawaban kepada stakeholders maka telah disusun Pedoman GCG, Board Manual, dan Code of Conduct, serta komite-komite Dewan Komisaris yang membantu fungsi pengawasan Dewan Komisaris .

Sebagai perwujudan nyata implementasi going green adalah adanya pelaksanaan sustainability management yang mendorong perusahaan untuk terus meningkatkan dan mengembangkan bisnisnya selaras dengan tuntutan lingkungan masyarakat, yaitu melalui 
upaya memperhatikan kondisi lingkungan, pemenuhan kebutuhan generasi sekarang dan mendatang, dan pengembangan keekonomian. Hal ini dapat diwujudkan melalui berbagai kegiatan sosial yang dilakukan oleh perusahaan seperti charity (kegiatan amal), kemitraan dengan industri kecil, dan pembinaan masyarakat melalui berbagai kegiatan lingkungan. Kegiatan sosial tersebut diwujudkan dengan adanya kegiatan Corporate Social Responsibility (CSR). Pemerintah Indonesia telah menyusun berbagai regulasi secara lengkap yang mengatur kegiatan CSR agar pelaksanaannya menjadi tepat sasaran dalam rangka mewujudkan butir Pancasila Sila kelima yaitu "keadilan sosial bagi seluruh rakyat Indonesia".

Pada tahun 2010, International Organization for Standardization (ISO) merilis serangkaian standar sukarela (voluntary standards) berupa ISO 26000 sebagai panduan bagi perusahaan-perusahaan untuk menerapkan CSR. Berbeda dengan standar ISO lainnya, ISO 26000 hanya memberikan panduan daripada berbagai persyaratan yang harus dipenuhi mengingat CSR bersifat lebih kualitatif dan standarnya tidak dapat disertifikasi. Untuk penerapan di Indonesia, pemerintah telah membekali perusahaan-perusahaan dalam negeri dengan berangkat perangkat regulasi yang berfungsi melindungi, membekali, dan memberikan panduan dalam pelaksanaan CSR. Adapun dasar hukum yang melekat pada CSR ini, Zulkifli (2018) mengidentifikasi dasar hukum kegiatan CSR sebagai berikut:

1. Undang-Undang Nomor 25 Tahun 2007 tentang Penanaman Modal.

2. Undang-Undang Nomor 40 Tahun 2007 tentang Perseroan Terbatas.

3. Keputusan Menteri Keuangan Nomor 232/KMK. 013/1989 tanggal 11 November 1989 tentang Pedoman Pembinaan Pengusaha konomi Lemah dan Koperasi melalui Badan Usaha Milik Negara (BUMN).

4. Peraturan Pemerintah Nomor 32 Tahun 1998 tentang Pembinaan dan Pengembangan Usaha Kecil.

5. Undang-Undang Nomor 19 Tahun 2003 tentang BUMN.

6. Undang-Undang Nomor 20 Tahun 2008 tentang Usaha Mikro, Kecil dan Menengah.

7. Undang-undang Nomor 13 Tahun 2011 Tentang Penanganan Fakir Miskin.

8. Peraturan Menteri Sosial RI Nomor 13 Tahun 2012 tentang Forum tanggungjawab dunia usaha dalam penyelenggaraan Kesejahteraan Sosial.

Saat ini sudah semakin banyak perusahaan-perusahaan dalam negeri yang melaksanakan CSR, konkritnya dapat dilihat dari gencarnya publikasi CSR di berbagai media cetak dan elektronik. Dalam rangka memotivasi perusahaan-perusahaan untuk lebih meningkatkan kualitas program CSR, telah ada Award yang dilaksanakan setiap tahunnya sebagai bentuk apresiasi atas komitmen perusahaan terhadap kepedulian lingkungannya. Salah satu lembaga independen yang melaksanakan Award rutin setiap tahun adalah Majalah bulanan CSR Indonesia dan Media Online CSR-
Indonesia.Com yang merupakan Award paling bergengsi di Indonesia saat ini. Di tahun 2019 tepatnya di SwissBel Resort - Sanur tanggal 30-31 Juli 2019 telah diberikan Award kepada 25 peraih pada 10 kategori (Cipta Karsa Mandiri, Reka Karsa Lingkungan, Bangun Karsa Rupa Sosial, Didaktika Pratama Unggul, Karsa Budaya Prima, Cipta Guna Sehati, Gagas Inova Karya, Gerak Mandiri Siaga, Daya Olahkarsa Pratama, dan Insan Gagas Gemilang). Diantara 25 peraih Award tersebut yang terpilih sebagai Best of The Best CSR Award yaitu PT. Kalimantan Prima Persada.

Pelaksanaan CSR tidak hanya dimonopoli oleh kelompok usaha, Pemerintah Pusat melalui pelaksanaan CSR Pemerintah Daerah dan kota telah pula melakukan berbagai upaya pengembangan potensi wilayahnya masing-masing. Upaya yang ditempuh yaitu melalui bentuk kemitraan antara Pemerintah Pusat dan Daerah, kelompok usaha, dan masyarakat melalui penetapan regulasi, diantaranya sebagai berikut:

1. Pelaksanaan CSR di Pemerintah Provinsi Jawa Timur

a. Dana yang digunakan menggunakan Pendapatan Asli Daerah (PAD) dan Dana Perimbangan.

b. Menerbitkan regulasi terkait Program Kemitraan Bina Lingkungan (PKBL) yang dituangkan dalam Peraturan Daerah Nomor 4 Tahun 2011 tentang Tanggungjawab Sosial Perusahaan dan Peraturan Gubernur Jawa Timur Nomor 42 Tahun 2012 tentang Tanggungjawab Sosial Perusahaan.

c. Alternaltif pinjaman daerah sebagaimana yang tertuang dalam Undang-Undang Nomor 22 Tahun 1999 Pasal 79 dan 81.

d. Alternatif pendanaan Pemerintah Daerah dengan menerbitkan instrumen keuangan ataupun obligasi daerah sebagaimana yang telah diatur dalam Undang-Undang Nomor 25 Tahun 1999 Pasal 11 dan 12 .

2. Pelaksanaan CSR di Pemerintah Provinsi Jawa Barat

a. Diterbitkan peraturan daerah di tahun 2013 tentang pedoman tanggung jawab sosial dan lingkungan perusahaan serta Program Kemitraan dan Bina Lingkungan (PKBL).

b. Diterbitkan Peraturan Gubernur Jawa Barat Nomor 30 Tahun 2011 tentang Fasilitasi Penyelenggaraan Tanggungjawab Sosial dan Lingkungan Perusahaan di Jawa Barat.

c. Sebagai bentuk sinergitas dan koordinasi pelaksanaan CSR dengan kelompok usaha dan sebagai bentuk pertanggungjawaban sosial maka diterbitkan Keputusan Gubernur Jawa Barat sebagai berikut:

- Nomor 536/Kep.791/Bapp/2011 tentang Tim Fasilitasi Penyelenggaraan Tanggung jawab Sosial dan Lingkungan Perusahaan di Jawa Barat.

- Nomor 537/Kep.791/Bapp/2011 tentang Duta CSR Dalam Penyelenggaraa Tanggungjawab Sosial dan Lingkungan Perusahaan di Jawa Barat. 
d. Dibentuk Forum CSR bekerjasama dengan perusahaan-perusahaan yang berada di wilayah Jawa Barat. Kegiatan Forum CSR ini sampai dengan tahun 2018 telah meresmikan 173 unit ruang kelas baru sekolah dan 9 unit puskesmas Pelayanan Obstetric Neonatal Emergensi Dasar (PONED) yang tersebar di 14 kabupaten/kota di Jawa Barat.

\section{KESIMPULAN}

Pelaksanaan corporate governance telah menjadi suatu keharusan bagi perusahaan untuk dapat menata kondisi internal perusahaan dengan lebih baik sehingga secara fundamental perusahaan lebih siap menghadapi persaingan dunia usaha yang semakin kompetitif. Untuk dapat meningkatkan keunggulan kompetitifnya, perusahaan harus memperhatikan 5 (lima) kekuatan utama perubahan yaitu sifat pekerjaan, pasar modal, persaingan pasar produk, bentuk organisasi, dan lingkungan organisasi. Pelaksanaan corporate governance ini merupakan modal dasar bagi perusahaan untuk dapat mengembangkan sustainability management melalui pengelolaan atas lingkungan, kebutuhan generasi sekarang dan mendatang, dan kegiatan ekonomi. Dalam lingkup nasional, sebagai hasil pelaksanaan corporate governance di Indonesia, berdasarkan laporan 2 (dua) tahunan ACGA Watch 2018 total skor corporate governance perusahaanperusahaan di Indonesia telah mengalami kenaikan dari 50,9\% di tahun 2016 menjadi 52\% di tahun 2018.

Pada dasawarsa terakhir ini telah muncul adanya konsep going green dan penerapannya yang lebih luas ke arah bagaimana perusahaan dapat lebih bermanfaat bagi lingkungan masyarakatnya. Bentuk nyata konsep tersebut yaitu adanya kegiatan Corporate Social Responsibility (CSR). Kegiatan CSR bahkan telah mempunyai aturan internasional yaitu dengan diberlakukannya ISO 26000 di tahun 2010 sedangkan dalam konteks di Indonesia telah disusun berbagai regulasi oleh Pemerintah Pusat dan Daerah yang dapat mendukung pelaksanaannya.

Sebagai bentuk nyata kontribusi terhadap masyarakat, pelaksanaan CSR bukan hanya dilaksanakan oleh perusahaan-perusahaan dalam negeri melainkan Pemerintah Daerah telah turut pula berpartisipasi. Bentuk CSR yang dilaksanakan oleh perusahaan diantaranya adalah kegiatan amal (charity), bina kemitraan dengan industri kecil, dan bina lingkungan melalui berbagai kegiatan sosial kemasyarakatan. Untuk dapat mendorong perusahaan-perusahaan untuk lebih meningkatkan program CRR, setiap tahun ada pemberian Award oleh lembaga independen Majalah bulanan CSR Indonesia dan Media Online CSRIndonesia.Com. Adapun bentuk pelaksanaan CSR oleh Pemerintah Daerah dilakukan melalui penetapan regulasi pro rakyat dan kerjasama dengan perusahaanperusahaan di wilayahnya seperti PONED, membangun ruang kelas baru sekolahan, dll. Sebagai bentuk nyata keberhasilan pelaksanaan CSR di Indonesia, berdasarkan laporan 2 (dua) tahunan ACGA Watch
2018 menunjukkan kenaikan indikator Environment and Social (E/S) dari 57,8\% di tahun 2016 menjadi $59,2 \%$ di tahun 2018. Berbagai dukungan regulasi dan kegiatan CSR yang telah terlaksana di lingkungan masyarakat tentunya banyak mendatangkan kemanfaatan sehingga butir Pancasila Sila kelima yaitu "keadilan sosial bagi seluruh rakya Indonesia" dapat segera terwujud.

\section{UCAPAN TERIMA KASIH}

Ucapan terima kasih Penulis sampaikan kepada semua pihak yang telah membantu penyelesaian karya tulis ini, khususnya kepada Magister Akuntansi Universitas Airlangga yang telah memberikan kesempatan kepada para mahasiswanya untuk lebih mengembangkan kemampuan penelitian sesuai dengan konsep Tri Dharma Perguruan Tinggi.

\section{DAFTAR PUSTAKA}

ACGA. (2018). Hard Decisions: Asia Faces Tough Choices in CG Reform. Retrieved from Hong Kong:https://www.acga-asia.org/cgwatch.php.

Agribisnis. (2016, 16 April). Penerapan Good Governance pada Sektor Publik, Swasta, dan Pemerintahan. Retrieved from http://agbsosek. blogspot.com/2016/04/penerapan-good-gover nance-padasektor.html.

AMERTA. (2018, 25 April). Perkembangan CSR di Indonesia. Retrieved from http://www.amerta. id/2018/04/25/1304/perkembangan-csr-diindonesia.php.

Bradley, M., Schipani, C., Sundaram, A., \& Walsh, J. (2000). The Purposes and Accountability of the Corporation in Contemporary Society: Corporate Governance at a Crossroads. Law and Contemporary Problems, 62. doi:10.2139/ ssrn. 220570.

Chen, J. (2019a, 18 April). Corporate Governance Definition. Retrieved from https://www. investopedia.com/terms/c/corporategovernance. asp.

Chen, J. (2019b, 27 November). Corporate Social Responsibility (CSR). Retrieved from https://www.investopedia.com/terms/c/corpsocial-responsibility.asp.

CSR-Indonesia. (2019, 31 Juli). Inilah 25 Peraih \#CSRINDONESIAAWARDS2019 dari 10 Kategori di Bali. Retrieved from https://csrindonesia.com/inilah-25-peraih-csrindonesia awards2019-dari-10-kategori-di-bali/.

Hoffman, A. (2001). From Heresy to Dogma: An Institutional History of Corporate Environmentalism, 320. Retrieved from https://www.sup.org/books/title/?id=3692.

Sites, W. (1998). Communitarian Theory and Community Development in The United States. Community Development Journal, 33(1), 57-65. doi:10.1093/cdj/33.1.57.

Taufik, A. R. (2019). Sustainable Reporting. PowerPoints Slides. Fakultas Ekonomi dan Bisnis. Universitas PGRI Madiun. Madiun. 
Zulkifli, A. (2018, 7 Januari). Dasar Hukum CSR.

Retrieved from https://bangazul.com/dasarhukum-csr/. 